\title{
Innovación docente en la asignatura "Teorías de la criminalidad": ¿se es alumno o se hace al alumno?
}

\section{Teaching innovation in the subject "Theories of crime": is it a student or is it made to the student?}

CRISTINA GARCía ARROYO

ORCID: https://orcid.org/0000-0002-4020-146X

Universidad de Sevilla

Departamento de Derecho penal

y ciencias criminales

cgarcia21@us.es

Fecha de recepción: 19/11/2019

Fecha de aceptación: 25/11/2019

DOI: http://dx.doi.org/10.12795/9788447221912.100

Pp.: 2242-2260 


\section{Resumen}

Las técnicas de innovación docente, cada día más presentes en nuestras aulas, son un reflejo de que otra forma de dar clase es posible. Abandonar las clases magistrales supone un enriquecimiento del profesor y una mejoría en la enseñanza universitaria. Los docentes tenemos en nuestra mano formar a profesionales con pensamiento crítico y altas capacidades de aprendizaje si mejoramos nuestra docencia.

En este capítulo analizamos un ciclo de mejora docente en el Grado de Criminología, en el que el trabajo con casos reales y actuales tiene un importante protagonismo. Los resultados muestran que los alumnos aprenden más fácilmente cuando reciben las explicaciones de manera más proactiva, con casos reales y que les despiertan su interés.

Palabras claves: Teorías de la Criminalidad, Grado en Criminología, Docencia Universitaria, Experimentación Docente Universitaria.

\section{Abstract}

The teaching innovation techniques, more and more present in our classrooms, are a reflection of the fact that another way of teaching is possible. Leaving the master classes means an enrichment of the teacher and an improvement in university teaching. We teachers have in our hands to train professionals with critical thinking and high learning skills if we improve our teaching.

In this chapter we analyse a cycle of educational improvement in the Degree in Criminology, in which work with real and current cases plays an important role. The results show that students learn more easily when they receive explanations in a more proactive way, with real cases that arouse their interest.

Key words: Theories of criminality, Degree in Criminology, University Teaching, University Teaching Experimentation.

Jornadas de Formación e Innovación Docente del Profesorado | № 2 (2019) Esta obra se distribuye con la licencia Creative Commons Reconocimiento-NoComercial-SinObraDerivada 4.0 Internacional (CC BY-NC-ND 4.0.) 


\section{Descripción del contexto}

La asignatura con la que he trabajado se llama "Teorías de la criminalidad", una asignatura troncal del Grado en criminología que se imparte en segundo curso del grado en turno único los lunes y martes de 15 a 16 h. y los miércoles de 15 a $17 \mathrm{~h}$.

Al enfrentarme al nuevo curso encontré un aula llena de estudiantes, más de ochenta en listas y más de setenta en clase, sentados, que acudían de forma continuada y con asiduidad a las mismas. El aula era una de las aulas más pequeñas de la facultad de Derecho y con lo único que contaba, aunque no sea poco, era con un ordenador, un proyector y una pizarra. Elementos en mi contra también había quizás demasiados para enfrentar un nuevo curso: era la primera vez que me enfrentaba a la asignatura de "Teorías de la criminalidad", había demasiados alumnos y en principio parecían muy ruidosos y mi momento personal era dificil pues me encontraba haciendo las últimas correcciones de mi tesis doctoral. Con este panorama nada podía hacer presagiar que podría hacerme con el peso de la clase y conseguir que mis alumnos siguieran viniendo motivados y con ganas de aprender, y aquí es donde entra en juego la innovación docente a la que en este curso yo le debo tanto.

\section{Diseño del ciclo de mejora para Teorías de la criminalidad}

En principio planteo iniciar el tema a enseñar desde el problema, proponiendo el análisis de casos reales, algo que considero que es más atractivo para el alumnado, para conseguir captar su atención y motivación desde el principio. De esta forma, en lugar de llevar a clase para trabajar en grupos fragmentos de los hechos probados de las sentencias del asesino "de la baraja", el asesino "de 
la ballesta" y el asesino de la "katana" que sería una metodología mucho más tradicional y clásica dentro de las ciencias jurídicas, organizo mi docencia para iniciar el ciclo proyectando documentales de aproximadamente 50 minutos de duración donde los alumnos puedan ver las conductas criminales de cada uno de los asesinos, las estudien y puedan sacar paralelismos en aras de poder determinar que la salud mental puede afectar a la hora de comisión de un delito y que en base a unos patrones de conductas, se pueden establecer teorías criminológicas útiles para la política criminal a seguir o para identificar como actuar con esas personas.

Con esta premisa de hacer que el interés del alumno exista desde el primer momento, que se acerque a la materia desde actividades visuales que no le supone un gran esfuerzo comprender porque las ve como una película, desarrollo el segundo ciclo de mejora a lo largo de un módulo de 8 horas de clases, es decir 2 semanas, justo coincidiendo con el tema más importante de la asignatura y que probablemente les despierte mayor interés, porque trabajaremos con casos conocidos y reales. Además de que, al ser alumnos del grado en criminología, alejarse de conceptos completamente jurídicos que pueden darse en la argumentación de una sentencia y entrar en una visión de psicología, psiquiatría o psicoanálisis, analizando con ellos la figura del delincuente y su modo de operar, les supone un atractivo mayor y cuento con más atención y motivación de su parte. Desde un inicio intenté crear grupos para trabajar en un clima de confianza y que exteriorizasen sus opiniones para que les den forma verbal y las intenten exponer de manera científica y aprendan entre ellos. El hecho de hacerlos salir de su zona de confianza y que tengan que exponer la idea ante el resto de la clase, hace que tengan que hacer el esfuerzo de razonarla y darle forma para expresarla verbalmente y que todos podamos entenderlos (Porlán, 2017). 
Si bien es cierto que dar al alumno las armas para pensar y tener un pensamiento a su vez crítico con el sistema o en este caso con las leyes y la forma de aplicarla, es importante, también lo es darle la confianza suficiente para que crea que en el aula puede decir lo que piensa siempre que su argumento sea razonado y se ajuste a los parámetros legales y, sobretodo, constitucionales. Hacerlos parte de las explicaciones, saber lo que piensan y por qué lo piensan me ha llevado a acercarme a su modelo de aprendizaje y por ello quería explicar la materia con métodos que para ellos fueran sencillos y familiares y no con textos que a veces no pueden llegar a comprender (Finkel, 2008). Con la visualización de audiovisuales pretendía conseguir que mis alumnos fueran conscientes de los trastornos mentales que existen y que tienen relevancia en las conductas criminales para que puedan analizarlos, agruparlos y saber la relevancia criminológica que tienen. De este modo, podrían llegar a comprender que toda la asignatura, desde su inicio más histórico hasta su parte más práctica o incluso la interrelación con otras asignaturas del Grado en Criminología, tiene una visión unitaria y que en este punto la ciencia se vuelve multidisciplar y que con unos conocimientos básicos de psiquiatría y psicología forense, ellos, como criminólogos, deben saber diferenciar los trastornos para poder determinar el modo de operar de los distintos criminales que podemos encontrar, porque sabiendo el "cómo actúa", puedo identificar a la persona desde un prisma más encaminado a la prevención y detención y también aportar datos para establecer una mejor política criminal en nuestras Leyes.

\section{Cuestionario de ideas iniciales}

Para comenzar el ciclo y poder ir adecuando las actividades pasé un cuestionario inicial para analizar sus conocimientos y ver que ideas me aportan. El cuestionario está constituido por preguntas que van de las más simples a 
las más complejas, intentado evitar lo abstracto en todas ellas (Porlán, 2017).

1. ¿Considera usted que la salud mental puede afectar a la hora de la comisión de un delito?

2. ¿Una enfermedad mental nos puede dar pistas para poder determinar una teoría de la criminalidad?

3. ¿Podría dar ejemplos de trastornos mentales que inciden en la criminalidad?

4. ¿Considera que los trastornos mentales se pueden agrupar? Y en caso afirmativo, ¿cuál considera que es la relevancia criminológica que debemos tener en cuenta dentro de esos grupos?

5. ¿Podría definir que es la psicopatología, el psicoanálisis y la psicología criminal?

Del análisis que realizo de este cuestionario consigo sacar datos de las preguntas 3,4 y 5 . Ya que con estas cuestiones puedo saber si mis alumnos han aprehendido las lecciones previas, el grado de motivación e interés por intentar dar contenido a lo que se le pregunta, aunque sean con otros conocimientos o hilando una pregunta con otra o poniendo ejemplos aunque no sepan agruparlos en las distintas categorías (Porlán, 2017). Tras analizarlas puedo hacer una mejor composición de las actividades que debo plantear en mi ciclo de mejora teniendo en cuenta el contenido que debía explicar, y que creía que ellos debían adquirir de manera dinámica y a veces llegando a conclusiones por ellos mismos para evitar que tuvieran que aprender de memoria contenidos que después no supieran llevar a la práctica. Las preguntas 1 y 2 no me aportan datos pues todos las contestaron bien ya que estratégicamente las realicé siendo las primeras las más sencillas para que el alumno tuviera la confianza de ver que las podía contestar.

Las escaleras iniciales que pude crear tras el análisis de las preguntas se representan en las figuras 1, 2 y 3 


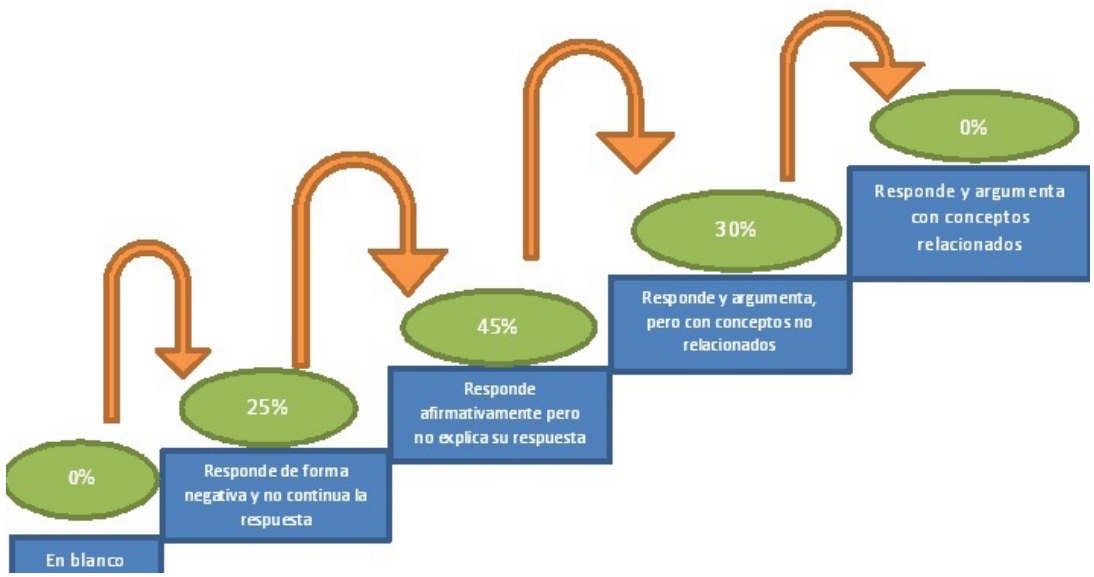

Figura 1. Escalera inicial de la pregunta 3

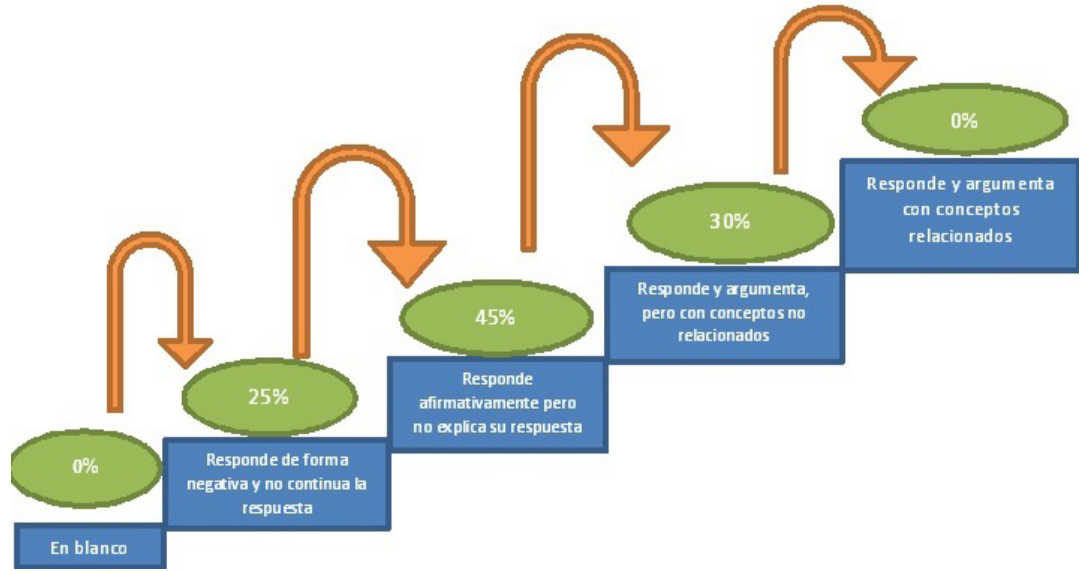

Figura 2. Escalera inicial de la pregunta 4

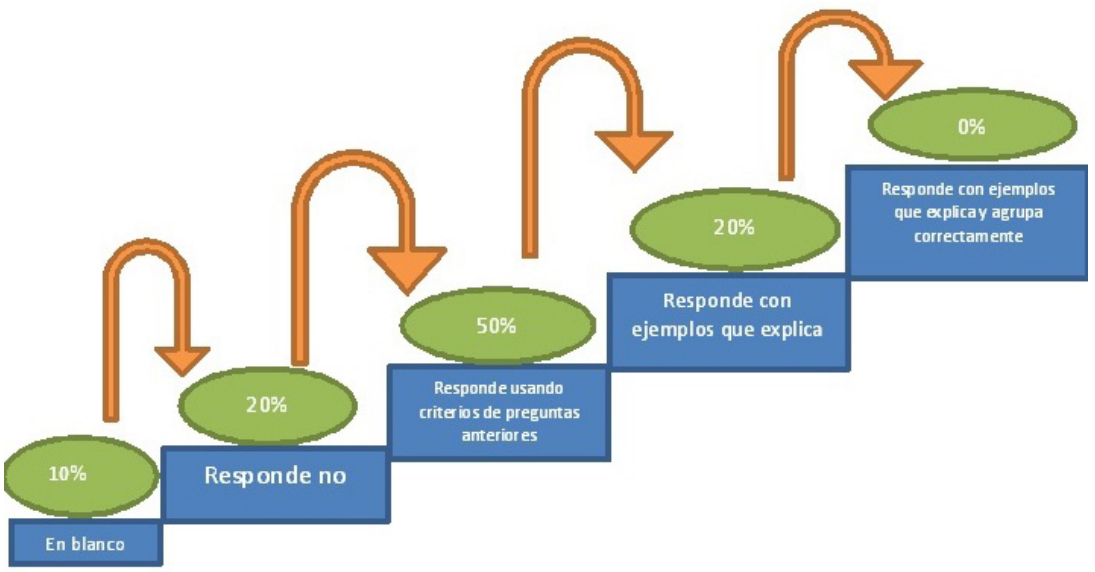

Figura 3. Escalera inicial de la pregunta 5

Jornadas de Formación e Innovación Docente del Profesorado I № 2 (2019) Esta obra se distribuye con la licencia Creative Commons Reconocimiento-NoComercial-SinObraDerivada 4.0 Internacional (CC BY-NC-ND 4.0.) 
Una vez que pude observar qué conocían mis alumnos y qué no y qué forma de razonar habían tenido, debía plantearme si los contenidos y las actividades que en un inicio había planeado para el desarrollo del CIMA eran las adecuadas teniendo los contenidos a enseñar (Bain, 2007).

\subsection{Propuesta de contenidos}

De este modo planteé el siguiente mapa de contenidos:

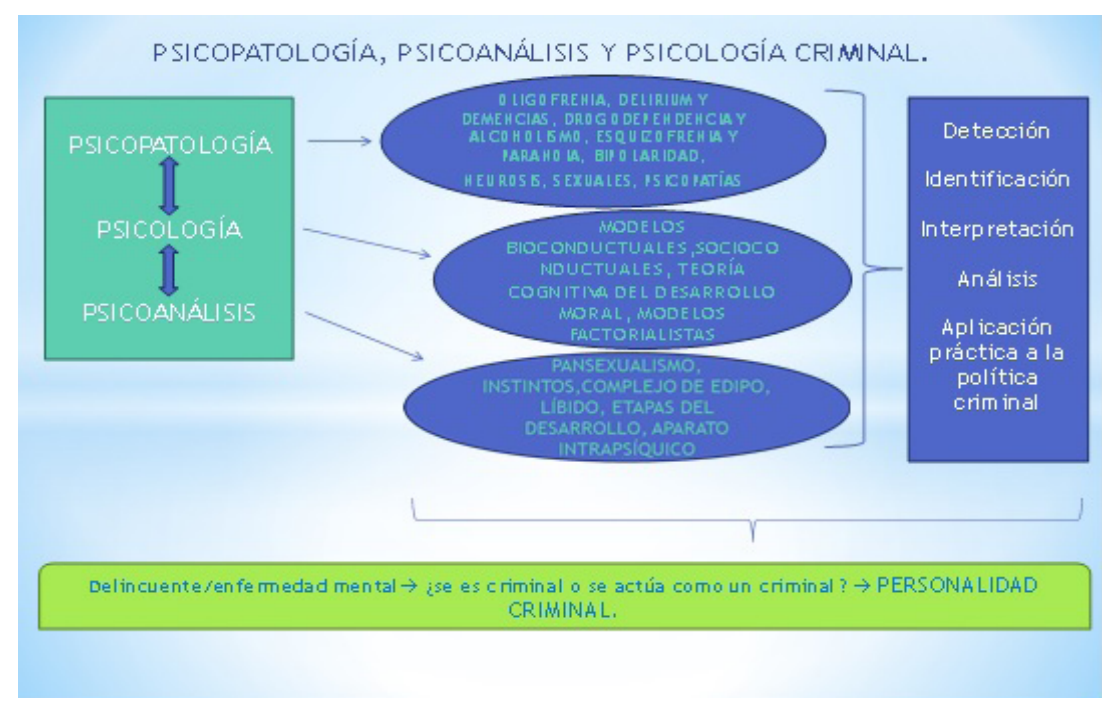

Figura 4. Mapa de contenidos

En el mapa de conocimientos que planteo, mis alumnos deben llegar a conocer que son la psicopatología, psicología y psicoanálisis criminal y saber que patologías engloban, como conocimientos conceptuales, y que de ellas se pueden derivar diversas formas de manifestación con factores en unas más sociales o culturales y en otras puramente patológicos. Desde la visión de los conocimientos procedimentales, deberían saber detectar e identificar, interpretar y analizar correctamente las patologías y las forma de desarrollo que ella contiene en cada conducta, para poder llegar a aplicar una política criminal 
adecuada a cada caso concreto; pero a su vez son muy importantes los contenidos actitudinales que cada alumno muestre al enfrentarse al contenido del ciclo, pues a veces muestran prejuicios preconcebidos sobre la delincuencia y las enfermedades mentales. Por ello, me parecía necesario que el alumno se pudiera enfrentar a los contenidos conceptuales y procedimentales desde una actitud positiva de aprendizaje y eliminar tendencias previas de creer que toda persona que comete un delito es un delincuente, porque sólo vaciándose de esos prejuicios previos podrían diferenciar si una persona es un criminal o por el contrario actúa como un criminal, para poder así llegar a determinar la personalidad criminal de cada sujeto con el que nos podamos encontrar.

\section{Modelo metodológico posible}

La metodología que planteé para que llegasen a alcanzar los conocimientos que creía que debían adquirir de una forma dinámica, a veces, autodidactica y siempre crítica, es la siguiente:

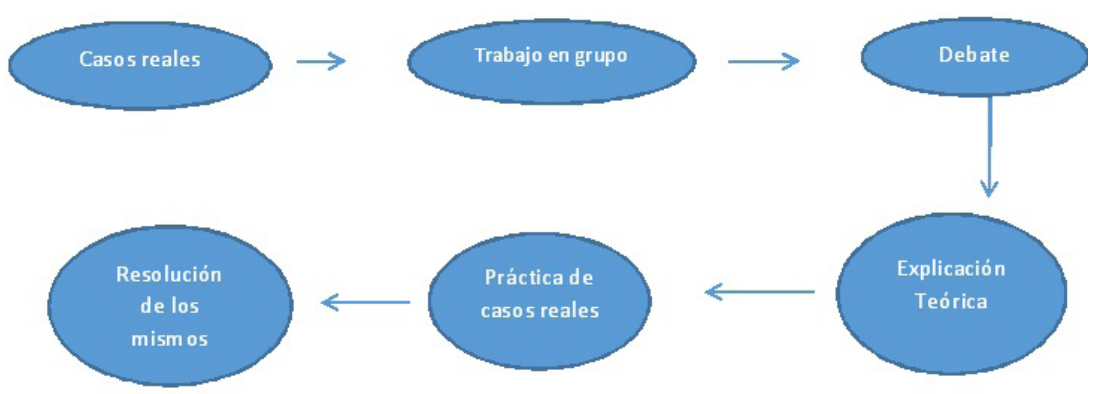

Figura 5. Modelo metodológico posible

Así pretendía con esta metodología captar la atención de los alumnos y su motivación desde el principio del ciclo, que fueran ellos quienes de forma autónoma intentasen sacar conclusiones y resoluciones a los casos, que entre todos expusieran las conclusiones que se sacasen, para posteriormente hacer la explicación teórica de la materia; una vez realizada ésta, proponerles otros supuestos 
reales (evaluables) y posteriormente resolver los mismos para que no quedasen dudas y pudiesen ver como desde el día 1 al día 8 han obtenido los conocimientos necesarios para aportar resoluciones y conclusiones más cientíicas y que sus argumentaciones pudieran ser más jurídicas (Bain, 2007).

\section{Secuencia de actividades}

Sesión 1:

Actividad 1: En las primeras actividades del ciclo que planteo casos reales, como quedó antedicho, les proyecto un documental sobre el "asesino de la baraja", disponible en el siguiente enlace: http:// www.rtve.es/alacarta/videos/victimas-del-misterio/ victimas-del-misterio-baraja/4543838/

Actividades 2 y 3: posteriormente a su visualización trabajarán en grupos para poder determinar los datos que consideren relevantes sobre las patologías que puede presentar el sujeto a analizar, para posteriormente llegar a debatir entre todas las conclusiones que pueden desgranarse del supuesto. Esta actividad se desarrolla en clase y aunque trabajen por grupos deben llegar a unas conclusiones que tienen que plasmar por escrito y entregarme; de esta forma puedo acercarme mejor a saber lo que han aprendido y como lo han hecho y si sus argumentos tienen carácter científico o simplemente se limitan a dar opiniones éticas o morales. En esta ocasión cuentan con mi ayuda en todo momento donde los guio cada vez que encuentren un obstáculo para continuar.

Sesión 2:

Actividad 5. Explicación teórica. Las explicaciones teóricas las planteo de forma dinámica, sin dejar de poner ejemplos, les pregunto e intento que ellos mismos sean los que puedan dar las respuestas a las cuestiones 
problemáticas que se plantean. Es importante en estas explicaciones conseguir que el alumnado mantenga el interés y puedan llevar el hilo argumental de la explicación.

Sesión 3:

Actividad 6. Explicación teórica. Pero siempre recurriendo a ejemplos que pudieran conocer por la prensa y haciéndoles participar en todo momento y preguntándoles sus opiniones.

Actividad 7 (opcional): Otra de las actividades que consideré adecuada para que llegaran a adquirir los conocimientos que planteaba en el mapa de contenidos, sobre todo los actitudinales, era que acudiesen a ver la película del "Joker" que estaba en ese momento de estreno en los cines y aprovechando que era la fiesta del cine podían ir a verla si querían. La idea era buena porque llegarian a entender muchos contenidos, pero al ser una actividad fuera del horario de clase y que les supondría un esfuerzo extra no la planteo como actividad obligatoria, pero si lanzo la idea para ver que ocurría.

Actividad 8. La última de las actividades de prácticas se trataría de casos reales sin decirles de que casos se tratan. Así, les pongo en la plataforma virtual la secuencia de hechos probados del "asesino de la Katana", de especial complejidad por la dureza del mismo, con la intención de que planteasen si posteriormente podían determinar las teorías criminales para el delincuente que se presentaba. Esta actividad la trabajan en casa y sería evaluada por mí, aunque lo resolvemos en clase posteriormente entre todos para evitar con ello que les quedasen dudas.

\section{Sesión 4:}

Actividad 9. Debate del caso práctico. Tras realizar la actividad 8 se debate en clase la resolución del supuesto práctico entre todos para evitar que queden dudas. 
Actividad 10. Síntesis. Recopilación de todo lo visto en clase desde una perspectiva global.

\section{Evaluación}

Para evaluar el aprendizaje conseguido durante el desarrollo del CIMA, tendré en cuenta todas las actividades a medida que se desarrollen y especialmente la comparación de los resultados obtenidos en el cuestionario inicial y final. Para evaluar el CIMA, utilizaré un cuestionario que responderán los estudiantes y mis propias reflexiones en mi diario.

Respecto a la calificación, sólo tendré en cuenta el segundo de los ejercicios obligatorios del ciclo, el del "asesino de la Katana", teniendo en cuenta tanto la resolución del caso escrito como la forma de defender en la clase su postura por parte de cada alumno. Como tengo un grupo numeroso de alumnos les dejo libertad de que se postulen voluntarios para resolverlos, premiando esto. El ejercicio supondrá un porcentaje de la nota final. Es cierto que cuando les evalúo el supuesto ponen mayor interés en hacerlo de forma más correcta sobretodo cuidando el vocabulario científico y la argumentación jurídica.

\section{Aplicación del CMD}

Como planteé, el segundo ciclo de mejora para la asignatura "Teorías de la criminalidad" tuvo una duración de 8 horas de docencia; la realidad de lo que ocurrió quedó del siguiente modo se expone a continuación.

\section{Relato del desarrollo}

La primera hora y media del CIMA, ya que este día tenía un módulo de dos horas, proyecté el documental sobre 
el asesino de la baraja, tal como estaba previsto. Al tratar con una asignatura en la que los sentimientos de cada uno o la capacidad de empatía puede afectar mucho, corría el riesgo de que en el documental saliesen muertes violentas y por ello no todos los alumnos pudieran soportar esas imágenes. A pesar de mi miedo, la clase transcurrió muy bien, ellos estuvieron muy pendientes del video. En los 40 minutos restantes organicé la clase en grupos para que trabajasen lo que habían visto en el documental y posteriormente se planteó un debate para poder desgranar los comportamientos del asesino y los posibles trastornos psíquicos y psicológicos que presentaba, en el que estuvieron muy participativos. Los estudiantes mostraron conocimientos mayores de los que yo esperaba que tendrían, por lo que se me hizo fácil llevarlos a la situación ideal para explicar el tema, contando con esos conocimientos previos y con la buena disposición que presentaban como mostraron durante el debate.

Las tres siguientes horas las dediqué a explicaciones teóricas-prácticas, explicando uno a uno los contenidos de la materia pero intentando que vieran las conexiones que tenían unos con otros y siempre poniendo ejemplos gráficos de casos reales, unos lo conocían, y otros no, pero en todo momento estaban atentos y participativos. Aunque noté que en estas clases en las que yo llevaba el gran peso, algunos se desconectaban más y solo copiaban la explicación. Para evitar eso, aludía a los ejemplos y pedía que ellos me los resolviesen. Las clases han sido muy dinámicas aún en este punto y creo que pudieron llegar al grado de conocimiento que yo pretendía. Aunque esto no lo podría saber hasta que no evaluase la práctica que les tenía preparada.

La sexta hora del CIMA la dediqué a la resolución de un caso práctico que previamente les había facilitado para que lo trabajasen en casa. Para la resolución del mismo dejé el peso de la clase en los alumnos, una chica salió 
voluntaria para corregirlo y el resto de los compañeros le hacían apreciaciones o preguntas o le corregían, por lo que vi que entre todos llegaban a nuevas conclusiones si no habían hecho bien el supuesto y entre ellos se daban las explicaciones del por qué era esa la respuesta correcta. La participación este día fue muy positiva y ellos estaban muy involucrados, el supuesto práctico era el del asesino de la "Katana" y me sorprendí gratamente porque no sólo resolvieron bien el caso, sino que se preocuparon por indagar sobre la vida de esta persona más allá de lo que se le pedía y pudimos entablar, además, un debate político criminal sobre formas de aplicación de la ley muy intenso e interesante, que creo que les sirvió mucho para poder ver que todo lo que vemos en clase pueden aplicarlo en su proyección profesional.

La séptima hora del CIMA hice un resumen de todo el temario y, como les propuse la actividad voluntaria de ver la película de "Joker" para que entendiesen muchas de las cosas que estábamos viendo en clase y comprendiesen que no se trataba de unas situaciones totalmente aisladas y que en la sociedad se pueden ver muchos casos como los que en clase podemos ver y hay que darles la mejor de las respuestas posibles, entablamos un debate con los alumnos que habían ido a ver la película, que sorprendentemente fueron casi todos los asistentes a la clase y planteamos la resolución de la personalidad criminal del personaje. Aunque en este caso fue más complicado que dieran exactamente con la respuesta, sí que 5 alumnos supieron identificar los problemas y los ítems básicos de la psicopatología del personaje, y sobre todo ver que con una persona que tiene una enfermedad mental no se puede actuar como si esa persona no la tuviera, sino que se tiene que reflejar en la política criminal de un Estado social. Aunque solamente fueran 5 alumnos, me alegré mucho porque me llegaron a decir que les explicaron a sus amigos la película y que creían que no sólo era un éxito en taquilla, sino que tenía un mensaje y una 
trascendencia que el resto de amigos que no cursaban esta asignatura no podían ver. Por lo que fue muy positivo para ellos y para mí.

La octava hora del CIMA pasamos el cuestionario final con las mismas preguntas que el inicial para valorar la progresión de los alumnos y hacer las escaleras y también pasé un cuestionario para valorar mi docencia.

\section{Evaluación del aprendizaje de los estudiantes}

El análisis de las escaleras finales (ver figuras 6, 7, 8 y 9) y la comparación entre las iniciales y las finales, me aportaron unos datos muy satisfactorios porque comprobé como habían subido todos de nivel sin mucho esfuerzo de estudio de memoria, que era algo que les causaba miedo según me manifestaban. Cierto es que no todos consiguieron llegar al nivel más alto, pero sí que todos tuvieron una gran progresión, sobretodo en la forma de pensar y argumentar que plasmaron de nuevo en los cuestionarios.

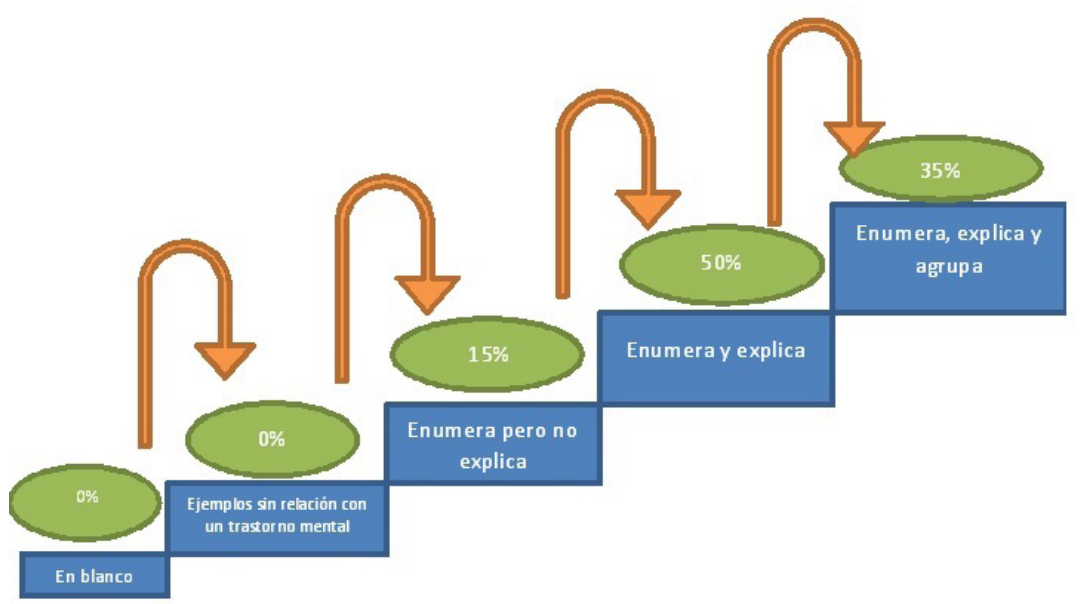

Figura 6. Escalera final pregunta 3

Jornadas de Formación e Innovación Docente del Profesorado | № 2 (2019) Esta obra se distribuye con la licencia Creative Commons Reconocimiento-NoComercial-SinObraDerivada 4.0 Internacional (CC BY-NC-ND 4.0.) 


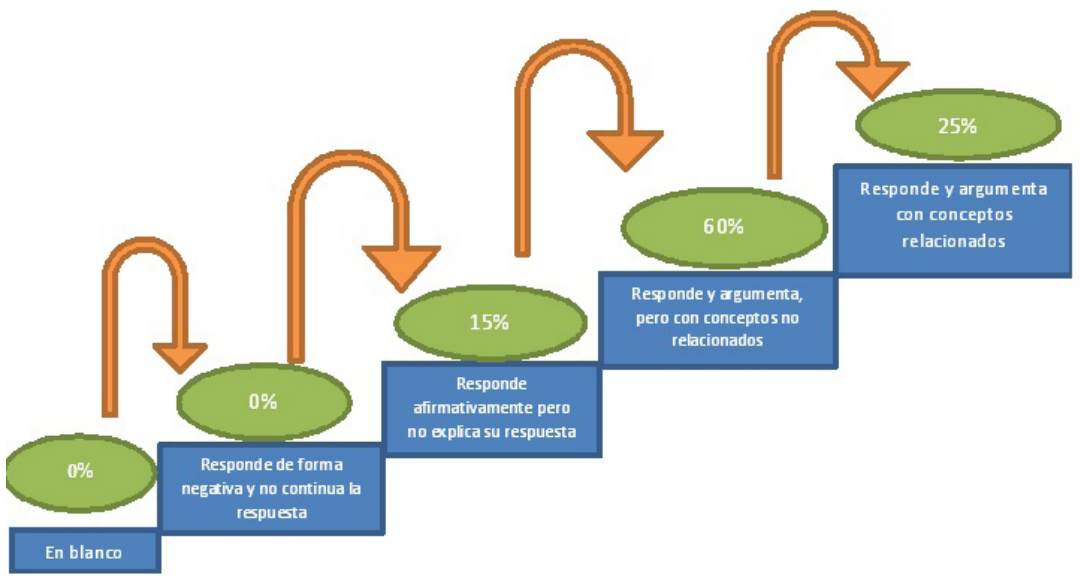

Figura 7. Escalera final pregunta 4

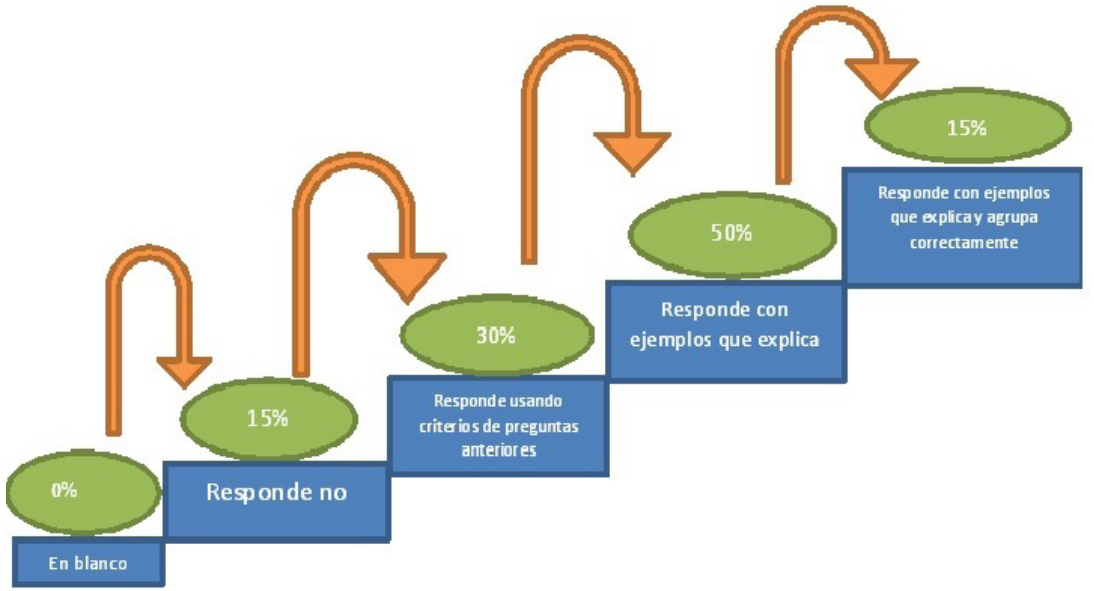

Figura 8. Escalera final pregunta 5

Por lo que se puede observar, entre las iniciales y las finales se da un aumento sustancial del nivel de la generalidad de los alumnos, los cuales sin un estudio profundo, intenso, detallado y memorístico han conseguido superar los obstáculos y obtener un mayor nivel de conocimiento a base de ver las cosas gráficamente y participar activamente en las clases con una mentalidad abierta y motivados, a aprender con una convicción firme de que lo que están aprendiendo algún día en el ejercicio de su profesión les será de utilidad (Bain, 2007). 


\section{Evaluación del cima puesto en práctica}

Después de la puesta en práctica de mi CIMA y observar y analizar el resultado obtenido en mis alumnos y en mi misma valoro positivamente haber realizado el esfuerzo de creer en la innovación, de leer y aprender técnicas nuevas. Pues como ya dijera Cotton Dana "quien se atreve a enseñar, nunca debe dejar de aprender".

Creo que siempre que el temario me permita adaptar mis clases a este sistema, lo haré así porque he visto una alta participación e interés en los alumnos y eso es positivo para el aprendizaje; pero aun cuando el temario no me permita hacer tantas actividades, sí que me quedo con poner videos en las prácticas, porque he visto que han prestado más atención y han aprendido más que cuando están leyendo un texto.

Cambiaría no cargarlos con tantos cuestionarios o actividades, por lo que tendré que hacer un esfuerzo de concreción, para que la actividad sea la más correcta con respecto del temario que tenga que impartir.

Yo he intentado enseñarles que una persona puede ser un criminal o actuar como un criminal por diversos motivos que tendrían que saber diferenciar, pero la aplicación de estas técnicas de innovación a mí me han enseñado que un alumno puede ser alumno por la condición de venir especialmente motivado, ser especialmente estudioso o despierto o porque nuestra asignatura le genere mayor o menor interés, pero que también hay otros alumnos a los que los docentes podemos hacer que "actúen como alumnos" y evitar que tengan una actitud pasiva en clase, mejorando nuestra docencia, generándoles motivación, haciéndoles participar y poniéndoles delante una visión de la asignatura atractiva. He podido comprobar como 
actuando de esta forma el rendimiento de mis alumnos ha mejorado y yo he podido quedar más contenta con mis clases, sobre todo cuando puedes escuchar a un alumno darte las gracias "por enseñarles a pensar", ahí reside la magia de la docencia, lo que de verdad importa. 


\section{Referencias bibliográficas}

Bain, K. (2007). Lo que hacen los mejores profesores universitarios. Valencia: Publicaciones Universidad de Valencia.

Finkel, D. (2008). Dar clase con la boca cerrada. Valencia: Publicaciones Universidad de Valencia.

Porlán, R. (Coord.) (2017). Enseñanza Universitaria. Cómo mejorarla. Madrid: Ediciones Morata.

Jornadas de Formación e Innovación Docente del Profesorado | № 2 (2019) Esta obra se distribuye con la licencia Creative Commons Reconocimiento-NoComercial-SinObraDerivada 4.0 Internacional (CC BY-NC-ND 4.0.) 